\title{
Fruit and vegetables and cancer risk: a review of southern European studies
}

\author{
Federica Turati ${ }^{1}$, Marta Rossi ${ }^{1}$, Claudio Pelucchi ${ }^{1}$, Fabio Levi ${ }^{2}$ and Carlo La Vecchia ${ }^{3 *}$ \\ ${ }^{1}$ Department of Epidemiology, IRCCS - Istituto di Ricerche Farmacologiche Mario Negri, Milan, Italy \\ ${ }^{2}$ Vaud Cancer Registry and Cancer Epidemiology Unit, Institute of Social and Preventive Medicine (IUMSP), \\ Lausanne University Hospital, Lausanne, Switzerland \\ ${ }^{3}$ Department of Clinical Sciences and Community Health, Università degli Studi di Milano, Via Vanzetti 5, \\ 20133 Milan, Italy
}

(Submitted 17 June 2014 - Final revision received 23 December 2014 - Accepted 5 January 2015)

\section{Abstract}

High intakes of fruit and vegetables may reduce the risk of cancer at several sites. Evidence has been derived mainly from case-control studies. We reviewed the relationship between consumption of vegetables and fruit and the risk of several common cancers in a network of Italian and Swiss case-control studies including over 10000 cases of fourteen different cancers and about 17000 controls. Data were suggestive of a protective role of vegetable intake on the risk of several common epithelial cancers. OR for the highest compared with the lowest levels of consumption ranged from 0.2 (larynx, oral cavity and pharynx) to 0.9 (prostate). Inverse associations were found for both raw and cooked vegetables, although for upper digestive tract cancers the former were somewhat stronger. Similar inverse associations were found for cruciferous vegetables. Frequent consumption of allium vegetables was also associated with reduced risk of several cancers. Fruit was a favourable correlate of the risk of several cancers, particularly of the upper digestive tract, with associations generally weaker than those reported for vegetables. A reduced risk of cancers of the digestive tract and larynx was found for high consumption of citrus fruit. Suggestive protections against several forms of cancer, mainly digestive tract cancers, were found for high consumption of apples and tomatoes. High intakes of fibres, flavonoids and proanthocyanidins were inversely related to various forms of cancer. In conclusion, data from our series of case-control studies suggested a favourable role of high intakes of fruit and vegetables in the risk of many common cancers, particularly of the digestive tract. This adds evidence to the indication that aspects of the Mediterranean diet may have a favourable impact not only on CVD, but also on several common (epithelial) cancers, particularly of the digestive tract.

\section{Key words: Cancer risk: Diet: Fruit: Vegetables}

The Mediterranean diet is a collection of eating patterns with different components, traditionally followed by populations from countries bordering the Mediterranean Sea, and is generally characterised by frequent consumption of fruit, vegetables, complex carbohydrates, pulses and fish; low consumption of meat and cheese; low-to-moderate amount of wine intake during meals; and use of olive oil for seasoning (as a major common characteristic). This dietary pattern has been suggested as a possible explanation for the longevity of populations from countries in the Mediterranean regions, and for the relatively low occurrence of CHD in such areas ${ }^{(1,2)}$.

The Mediterranean diet as a whole and some of its aspects have been inversely related to the risk of cancer ${ }^{(3-8)}$. In particular, high intakes of fruit and vegetables have been related to a reduced risk of cancer at several sites, with associations stronger for cancers of digestive and respiratory tracts and somewhat

Abbreviations: FRAP, ferric reducing-antioxidant power; TEAC, Trolox equivalent antioxidant capacity; TRAP, total radical-trapping antioxidant parameter.

* Corresponding author: Professor C. La Vecchia, fax +3902 33200231, email carlo.lavecchia@unimi.it

Publication of these papers was supported by unrestricted educational grants from Federación Española de Sociedades de Nutrición, Alimentación y Dietética (FESNAD), International Nut and Dried Fruit Council (INC), International Union of Nutritional Sciences (IUNS), Fundación Iberoamericana de Nutrición (FINUT), Centro de Investigación Biomédica en Red de la Fisiopatología de la Obesidad y Nutrición (CIBERobn) and Centro Interuniversitario di Ricerca sulle Culture Alimentari Mediterranee (Ciiscam). The papers included in this supplement were invited by the Guest Editors and have undergone the standard journal formal review process. They may be cited. The Guest Editors declare that Salas-Salvadó is a nonpaid member of the World Forum for Nutrition Research and Dissemination of the International Nut and Dried Fruit Council. Angel Gil is President of the Fundación Iberomericana de Nutrición, which is a non-paid honorary position. Lluis Serra-Majem is the President of the Scientific Committee of the Mediterranean Diet Foundation and Scientific Director of the CIISCAM (Centro Interuniversitario di Ricerca sulle Culture Alimentari Mediterranee), Universita La Sapienza di Roma which are both non-paid, honorary positions. Goretti Guasch is the Executive Director and Member of the Executive Committee of the International Nut and Dried Fruit Council, which is a paid position. Mònica Bulló declares no conflict of interest. 
weaker for hormone-related cancers. However, most of the epidemiological evidence supporting a favourable role of vegetables and fruit is derived from case-control studies, whereas evidence from cohort studies is less convincing ${ }^{(9)}$

In the present review, we discuss and summarise the main findings on the relationship between vegetable and fruit consumption and cancer risk from an integrated series of multi-centric case-control studies conducted in Italy and Switzerland.

\section{Methods}

Since the early 1990s, a series of case-control studies of various neoplasms were conducted in Italy and Switzerland. These included 768 cases of oral and pharyngeal cancer ${ }^{(10)}$, 198 cases of nasopharyngeal cancer ${ }^{(11)}, 304$ cases of oesopha${\text { geal } \text { cancer }^{(12)}, 230 \text { cases of stomach cancer }}^{(13)}, 1953$ cases of colorectal cancer $^{(14)}, 185$ cases of liver cancer ${ }^{(15)}, 326$ cases of pancreatic cancer ${ }^{(16)}, 527$ cases of laryngeal cancer ${ }^{(17)}, 2569$ cases of breast cancer ${ }^{(18)}, 454$ cases of endometrial cancer $^{(19)}, 1031$ cases of ovarian cancer ${ }^{(20)}, 1294$ cases of prostate cancer $^{(21)}$ and 767 cases of kidney cancer $^{(22)}, 190$ cases of non-Hodgkin's lymphomas ${ }^{(23)}$ (Table 1); and a total of over 17000 controls. Cases were individuals admitted to major teaching and general hospitals with incident, histologically confirmed cancers. Controls were patients with no history of cancer, admitted to the same hospitals for acute nonneoplastic condition, unrelated to known risk factors for the corresponding cancer site or dietary modification. The study protocols were revised and approved by the ethical committees of the hospitals involved, according to the regulations at the time of study conduction. All participants gave informed consent.
Trained personnel interviewed cases and controls during their hospital stay using a structured questionnaire, including information on sociodemographic characteristics, anthropometric measures, lifestyle habits (e.g. tobacco smoking and alcohol drinking), dietary habits, personal medical history, family history of cancer, and, for women, menstrual and reproductive factors, use of oral contraceptives and hormone replacement therapy. The usual diet of the subjects 2 years before diagnosis (or hospital admission, for controls) was investigated using a reproducible and valid $\mathrm{FFQ}^{(24,25)}$, including seventyeight food items and beverages. Subjects were asked to indicate the average weekly frequency of consumption for each dietary item, and the seasonal consumption for a few vegetables and fruit, with the corresponding duration.

OR, and the corresponding $95 \% \mathrm{CI}$, for quintiles (computed among controls) of vegetable or fruit intake were estimated by multiple logistic regression models. For nasopharyngeal and liver cancers and non-Hodgkin's lymphomas, subjects were grouped according to quartiles of intake. Although models were derived independently for each cancer site, according to their potential confounding factors, all of them included terms for age, sex (when appropriate), study centre or area of residence, education and energy intake. Models for liver and breast cancers were also adjusted for alcohol drinking; models for stomach cancer were adjusted for tobacco smoking; and models for cancers of oral cavity and pharynx, nasopharynx, oesophagus, pancreas, larynx and kidney were adjusted for both alcohol drinking and tobacco smoking. Allowance for BMI or physical activity was performed for cancers of oral cavity and pharynx, pancreas, kidney and colorectum. A term for hepatitis was included in the models for liver cancer (B and/or C viruses) and non-Hodgkin's lymphomas (C virus). Concerning female hormone-related cancers, OR for breast cancer were also adjusted for parity,

Table 1. Data on selected cancers for the highest $v$. the lowest levels of consumption of cruciferous and allium vegetables in Italy and Switzerland, 1991-2009 (Odds ratios, and $95 \%$ confidence intervals)

\begin{tabular}{|c|c|c|c|c|c|c|c|}
\hline \multirow[b]{3}{*}{ Cancer sites } & \multirow[b]{3}{*}{$n$} & \multirow{2}{*}{\multicolumn{2}{|c|}{$\begin{array}{c}\text { Cruciferous } \\
\text { vegetables }(\geq 1 \mathrm{v} \text {. } \\
<1 \text { portion/week })\end{array}$}} & \multicolumn{4}{|c|}{ Allium vegetables } \\
\hline & & & & \multicolumn{2}{|c|}{$\begin{array}{c}\text { Onion ( } \geq 7 \mathrm{v} . \\
0 \text { portions/week) }\end{array}$} & \multicolumn{2}{|c|}{$\begin{array}{l}\text { Garlic (high } v \text {. } \\
\text { no or low use }{ }^{\star} \text { ) }\end{array}$} \\
\hline & & OR & $95 \% \mathrm{Cl}$ & OR & $95 \% \mathrm{Cl}$ & OR & $95 \% \mathrm{Cl}$ \\
\hline Oral cavity and pharynx & 768 & 0.83 & $0.70,0.98$ & 0.16 & $0.06,0.46$ & 0.61 & $0.44,0.85$ \\
\hline Nasopharynx & 198 & - & & - & & - & \\
\hline Oesophagus & 304 & 0.72 & $0.52,0.99$ & 0.12 & $0.02,0.58$ & 0.43 & $0.28,0.67$ \\
\hline Stomach† & 230 & 0.90 & $0.61,1.30$ & 0.59 & $0.25,1.41$ & 0.69 & $0.41,1.15$ \\
\hline Colorectum & 1953 & 0.83 & $0.74,0.94$ & 0.44 & $0.28,0.67$ & 0.74 & $0.63,0.86$ \\
\hline Liver & 185 & 0.72 & $0.47,1.11$ & - & & - & \\
\hline Pancreas & 326 & 0.90 & $0.63,1.30$ & - & & - & \\
\hline Larynx & 527 & 0.84 & $0.67,1.05$ & 0.17 & $0.05,0.61$ & 0.56 & $0.38,0.82$ \\
\hline Breast & 2569 & 0.83 & $0.74,0.94$ & 0.75 & $0.50,1.12$ & 0.90 & $0.77,1.05$ \\
\hline Endometrium $†$ & 454 & 0.93 & $0.68,1.27$ & 0.40 & $0.22,0.72$ & 0.62 & $0.42,0.92$ \\
\hline Ovary & 1031 & 0.91 & $0.76,1.11$ & 0.27 & $0.08,0.85$ & 0.78 & $0.62,0.98$ \\
\hline Prostate & 1294 & 0.87 & $0.70,1.09$ & 0.29 & $0.07,1.03$ & 0.81 & $0.64,1.00$ \\
\hline Kidney & 767 & 0.68 & $0.54,0.84$ & 0.62 & $0 \cdot 18,2 \cdot 10$ & 0.69 & $0.53,0.92$ \\
\hline Non-Hodgkin's lymphomas & 190 & - & & - & & - & \\
\hline
\end{tabular}

*Qualitative variable scored as 1 for 'non-use or low use', 2 for 'intermediate use', and 3 for 'high use'. $\dagger$ For endometrial and stomach cancer only, the OR is for consuming $\geq 2 \mathrm{v}$. 0 portions/week of onion. 


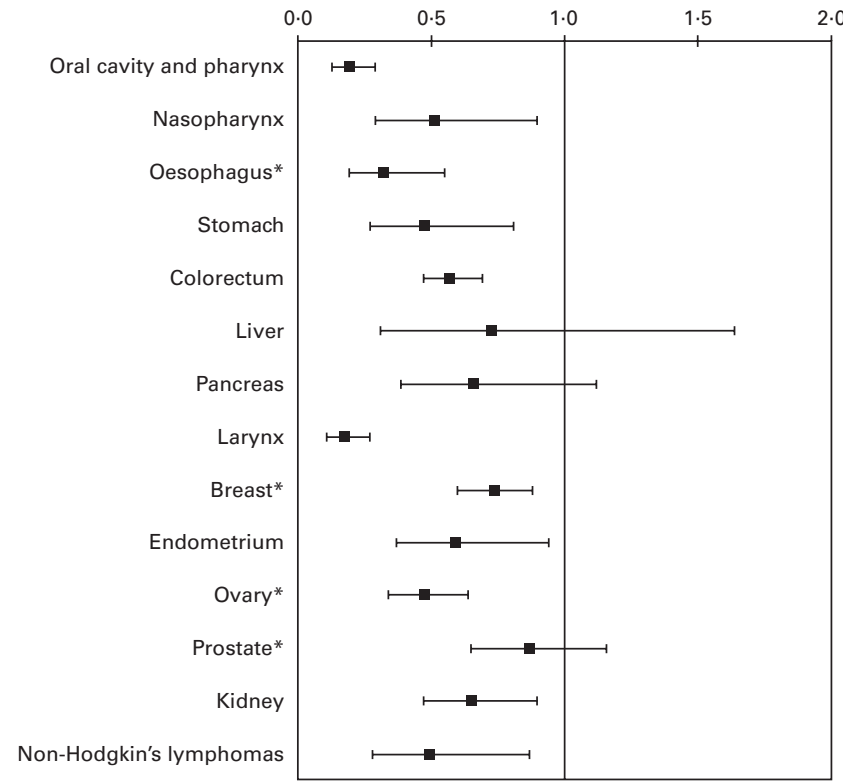

Fig. 1. OR and $95 \% \mathrm{Cl}$ of selected cancers for the highest quintile $v$. the lowest quintile of vegetable consumption for all cancer sites, except for nasopharyngeal and liver cancers, and non-Hodgkin's lymphomas (quartiles). Italy and Switzerland, 1991-2009. *Raw vegetables.

those for ovarian cancer were adjusted for parity and oral contraceptive use, and those for endometrial cancer were adjusted for parity, oral contraceptive use, hormone replacement therapy, age at menarche, menopausal status and history of diabetes.

In the present review, we also provided results on selected vegetables or fruit of specific interest, i.e. those that are cheap and easy to store and transport, and thus the most frequently consumed.

\section{Vegetables}

The present data supported a protective role of high intake of vegetables in the risk of several common epithelial cancers (Fig. 1). In particular, the OR for the highest compared with the lowest levels of vegetable intake were 0.19 (95\% CI $0.13,0.29)$ for oral and pharyngeal cancer, 0.51 (95\% CI $0 \cdot 29,0 \cdot 90)$ for nasopharyngeal cancer, 0.32 (95\% CI $0 \cdot 19$, 0.55) for oesophageal cancer, 0.47 (95\% CI $0.27,0.81)$ for stomach cancer, $0.57(95 \%$ CI $0.47,0.69)$ for colorectal cancer, $0.72(95 \%$ CI $0.31,1.64)$ for liver cancer, $0.66(95 \%$ CI $0.39,1.12$ ) for pancreatic cancer and 0.17 (95\% CI 0.11 , 0.27) for laryngeal cancer. Among hormone-related cancers, breast, endometrial and ovarian cancers were inversely related to vegetable consumption, with OR of 0.73 (95\% CI 0.60 , 0.88 ), 0.59 (95\% CI 0.37, 0.94) and 0.47 (95\% CI 0.34, 0.64), respectively, whereas the estimate for prostate cancer was below unity (i.e. 0.87), but not significant. A favourable role of vegetable intake was also observed for kidney cancer (OR 0.65, 95\% CI 0.47, 0.90), as well as for non-Hodgkin's lymphomas (OR 0.49, $95 \%$ CI 0.28, 0.87).

Cooking food may destroy selected nutrients and enzymes, alter the structure and thus digestibility of the food, and create by-products. However, for some foods and food components (e.g. lycopene), cooking not only kills potentially harmful organisms, but also actually improves the bioavailability of certain nutrients and digestibility. Findings from our case-control studies supported inverse relationships between consumption of both raw and cooked vegetables and the risk of cancers, with the exception of breast cancer, for which an inverse association was found essentially for raw vegetables. In general, these relationships appeared somewhat stronger for raw than cooked vegetables for upper digestive tract cancers. OR for the highest $v$. the lowest intakes (generally quintiles) of raw and cooked vegetables were respectively, 0.25 and 0.50 for oral and pharyngeal cancer ${ }^{(10)}, 0.54$ and 0.67 for nasopharyngeal cancer ${ }^{(11)}, 0.32$ and 0.79 for oesophageal cancer $^{(12)}, 0.59$ and 0.57 for colorectal cancer ${ }^{(14)}, 0.77$ and 0.57 for pancreatic cancer ${ }^{(16)}, 0.22$ and 0.32 for laryngeal cancer $^{(17)}, 0.73$ and 0.96 for breast cancer ${ }^{(18)}, 0.47$ and 0.65 for ovarian cancer ${ }^{(20)}, 0.87$ and 0.74 for prostate cancer ${ }^{(21)}$, and 0.74 and 0.68 for kidney cancer ${ }^{(22)}$.

Cruciferous vegetables (cabbages, cauliflowers, broccoli, brussels sprouts and turnip greens) are important sources of sulphur-containing compounds (glucosinolates), whose major breakdown products (isothiocyanates and indoles) have anti-carcinogenic properties in in vitro and animal studies $^{(26)}$. Our data showed significantly reduced OR for regular ( $\geq 1$ portion/week) compared with no/occasional intake for cancers of the oral cavity and pharynx, oesophagus, colorectum, breast and kidney (Table 1$)^{(26)}$.

Frequent consumption of allium vegetables, particularly onion, represents a peculiar feature of the Mediterranean diet. Garlic and onion are a source of several organosulphur compounds in addition to amino acids, vitamins and micronutrients, and have anti-inflammatory, anti-thrombotic,

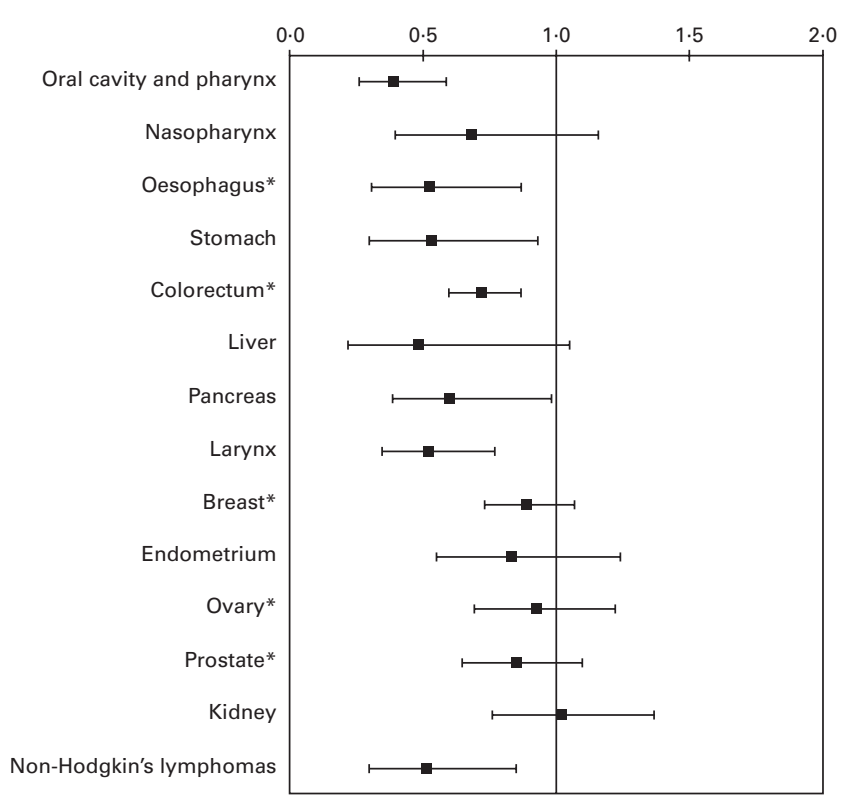

Fig. 2. OR and $95 \% \mathrm{Cl}$ of selected cancers for the highest quintile $v$. the lowest quintile of fruit consumption for all cancer sites, except for nasopharyngeal and liver cancers, and non-Hodgkin's lymphomas (quartiles). Italy and Switzerland, 1991-2009. *Non-citrus fruits. 


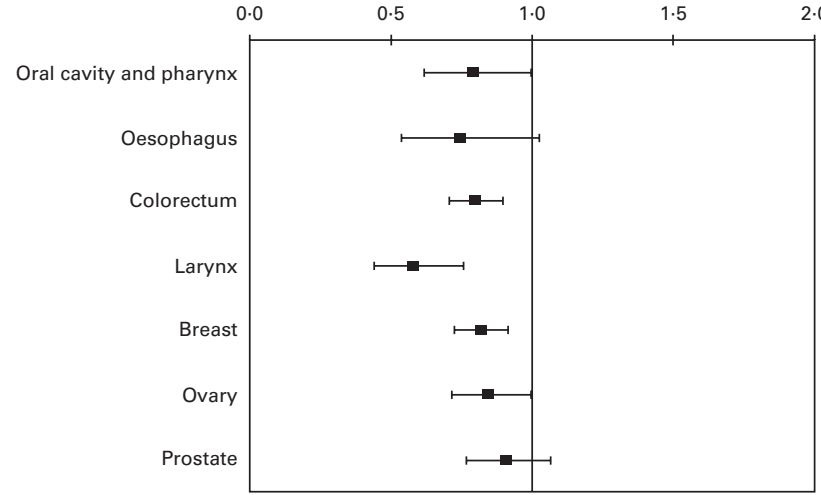

Fig. 3. OR and $95 \% \mathrm{Cl}$ of selected cancers for consumption of $\geq 1 \mathrm{v}$. $<1$ apple/d. Italy, 1991-2002.

cholesterol-lowering and antioxidant effects ${ }^{(27,28)}$. Data from the present series of case-control studies support a favourable role of allium vegetable intake in cancer risk in Italy and Switzerland (Table 1). In particular, a significantly decreased risk for high intakes of onion and garlic was found for cancers of oral cavity and pharynx, oesophagus, colorectum, larynx, endometrium, ovary and kidney (only garlic) ${ }^{(27-29)}$.

\section{Fruit}

Fruit was a favourable correlate of the risk of several cancers, particularly of the digestive tract; however, associations were generally weaker than for vegetables. The OR for the highest compared with the lowest levels of intake were 0.39 (95\% CI $0 \cdot 26,0.59)$ for oral and pharyngeal cancer, 0.52 (95\% CI 0.31 , 0.87 ) for oesophageal cancer, 0.53 (95\% CI $0.30,0.93)$ for stomach cancer, $0.72(95 \%$ CI $0.60,0.87)$ for colorectal cancer, 0.60 (95\% CI $0.39,0.98)$ for pancreatic cancer and 0.52 (95\% CI $0.35,0.77)$ for laryngeal cancer (Fig. 2). A strong association with fruit was also found for non-Hodgkin's lymphomas (OR 0.51, 95\% CI 0.30, 0.85). The OR for liver cancer was around 0.5 ; however, it did not reach statistical significance. No appreciable association was observed for hormone-related and kidney cancers, with OR ranging from 0.83 (endometrial cancer) to 1.02 (kidney cancer).

A reduced risk of cancers of the digestive tract and larynx was observed in our data for increasing intakes of citrus fruit, rich in vitamin C, flavanones and other compounds with antioxidant, anti-mutagenic and anti-proliferative properties ${ }^{(30)}$. Compared with subjects consuming less than 1 portion of citrus fruit per week, the OR for those consuming 4 or more portions per week were 0.47 (95\% CI $0.36,0.61)$ for oral cavity and pharyngeal cancer, 0.42 (95\% CI $0.25,0.70)$ for oesophageal cancer, 0.69 (95\% CI 0.52, 0.92) for stomach cancer, $0.82(95 \%$ CI $0.72,0.93)$ for colorectal cancer and 0.55 (95\% CI $0.37,0.83)$ for laryngeal cancer. For other neoplasms, including cancers of breast, ovary, endometrium, prostate and kidney, no evidence of a beneficial effect of citrus fruit was found ${ }^{(30)}$.
Apples contain several phytochemicals, including flavonoids and phenolic acids, and, when compared with other fruits, they had the second highest level of antioxidant activity (after cranberries) and phenolic compounds, and the highest level of free phenolic compounds ${ }^{(31)}$. Subjects eating at least one apple a day had a reduced risk of cancers of oral cavity and pharynx (OR 0.79, 95\% CI 0.62, 1.00), colorectum (OR $0.80,95 \%$ CI $0.71,0.90$ ), larynx (OR $0.58,95 \%$ CI 0.44 , 0.76 ), breast (OR $0.82,95 \%$ CI $0.73,0.92$ ) and ovary (OR $0 \cdot 85,95 \% \mathrm{CI} 0 \cdot 72,1 \cdot 00)$. OR for oesophageal and prostate cancers were 0.75 (95\% CI $0.54,1.03)$ and 0.91 (95\% CI 0.77 , 1.07), respectively (Fig. 3) ${ }^{(31)}$

Tomatoes are a typical aspect of the Italian diet and, in general, of the Mediterranean diet, and are the main source of lycopene, a carotenoid with strong antioxidant properties that is not converted to vitamin $\mathrm{A}^{(32)}$. Compared with the lowest quintile of tomato intake, the OR of colorectal cancer for the highest quintile was $0.8(95 \% \text { CI } 0.6,0 \cdot 9)^{(32)}$. We estimated an OR of 0.65 (95\% CI $0.4,1.0)$ for cancer of oral cavity, pharynx and oesophagus, and one of 0.43 (95\% CI $0.3,0.6)$ for cancer of the stomach, for the highest compared with the lowest quartile of intake ${ }^{(33)}$.

\section{Fibres, flavonoids and proanthocyanidins}

With regard to specific components of vegetables and fruit, dietary fibre intake was inversely associated with most cancers considered, particularly with those of the digestive tract (Fig. 4). The OR for an increment of intake equal to the difference between the 80th and 20th percentile were 0.51 (95\% CI 0.40,

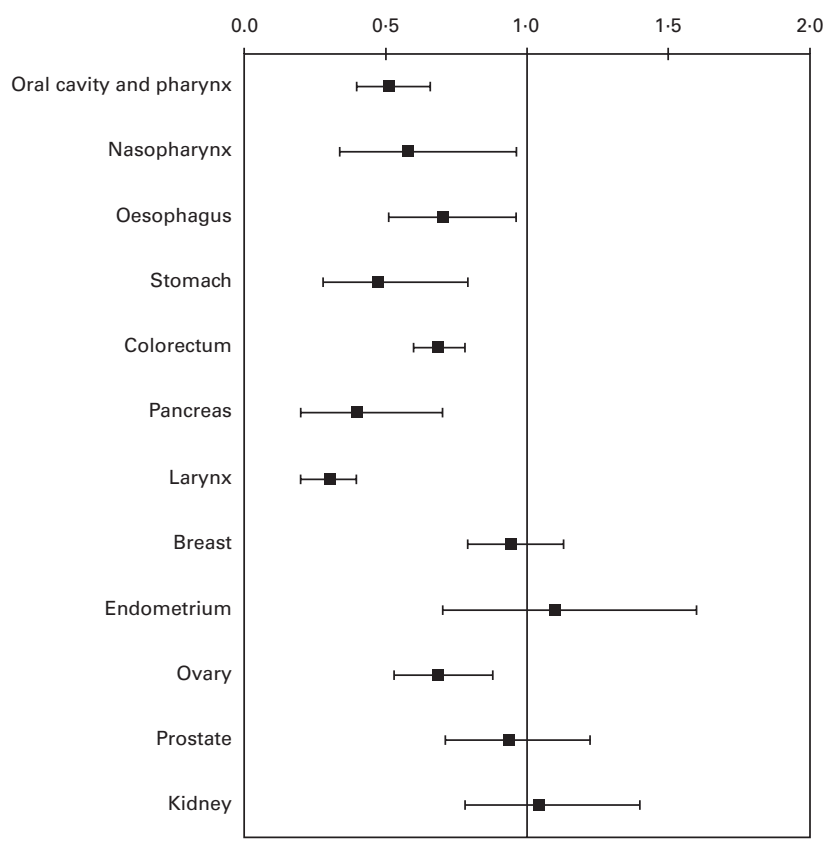

Fig. 4. OR and $95 \% \mathrm{Cl}$ of selected cancers for fibre consumption. Italy and Switzerland, 1991-2009. Comparisons: difference between 80th and 20th percentile of the control distribution for oral and pharyngeal, oesophageal and colorectal cancer; 4 th $v$. 1st quartile of consumption for nasopharyngeal cancer; 5 th $v$. 1st quintile of consumption for other cancer sites. 


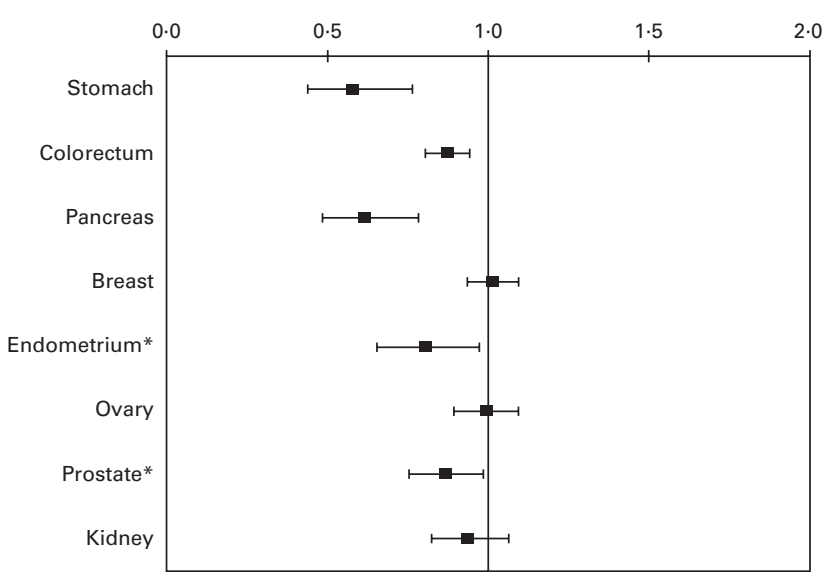

Fig. 5. OR for an increment of proanthocyanidins with $\geq 3$ mers intake equal to the difference between the 80th and 20th percentile. Italy and Switzerland, 1991-2009. ${ }^{*}$ Monomers and dimers.

0.66) for oral and pharyngeal cancer, $0 \cdot 70$ (95\% CI 0.51, 0.96) for oesophageal cancer and 0.68 (95\% CI 0.60, 0.78) for colorectal cancer. The OR for the highest $v$. the lowest categories of intake were 0.58 (95\% CI $0.34,0.96)$ for nasopharyngeal cancer, 0.47 (95\% CI $0.28,0.79)$ for stomach cancer, 0.4 (95\% CI $0.2,0.7)$ for pancreatic cancer, $0.3(95 \%$ CI $0.2,0.4)$ for laryngeal cancer and 0.68 (95\% CI 0.53, 0.88) for ovarian cancer. Conversely, a lack of association was observed for cancers of breast, endometrium, prostate and kidney ${ }^{(34-44)}$

Results on flavonoids from the present series of Italian and Swiss case-control studies showed a significant protective role of flavanones on upper aero-digestive tract cancers (OR for the highest $v$. the lowest quintiles of intake $0.51,95 \% \mathrm{CI}$ $0.37,0.71$ for oral cavity and pharyngeal cancer; $0.38,95 \%$ CI $0.23,0.66$ for oesophageal cancer; $0.60,95 \%$ CI $0.41,0.89$ for laryngeal cancer), flavonols (OR $0.64,95 \%$ CI $0.54,0.77$ ) and anthocyanidins (OR 0.67, 95\% CI 0.54, 0.82) on colorectal cancer, flavonols (OR 0.80, 95\% CI 0.66, 0.98) and flavones (OR 0.81, 95\% CI 0.66, 0.98) on breast cancer, and flavonols (OR 0.63, 95\% CI 0.47, 0.84) and isoflavones (OR 0.51, $95 \%$ CI $0.37,0.69)$ on ovarian cancer ${ }^{(45,46)}$. Specific results on proanthocyanidins are shown in Fig. 5. Significant inverse associations were found for cancers of the stomach, colorectum, pancreas, endometrium and prostate, with OR for an increment of intake equal to the difference between the 20th and the 80th percentile of 0.58 (95\% CI $0.44,0.77)$ for stomach cancer ${ }^{(47)}, 0 \cdot 88$ (95\% CI $\left.0 \cdot 81,0 \cdot 95\right)$ for colorectal cancer $^{(48)}, 0.62(95 \%$ CI $0.49,0.79)$ for pancreatic cancer ${ }^{(49)}$, 0.81 for endometrial cancer $(95 \% \text { CI } 0.66,0.98)^{(50)}$ and 0.87 (95\% CI $0 \cdot 76,0.99)$ for prostate cancer (unpublished results).

\section{Discussion}

Data from this integrated network of studies support a favourable role of vegetable intake on the risk of several common cancers, particularly of the digestive tract. Fruit intake was inversely related to the risk of digestive tract cancers as well, with associations generally less stronger than those for vegetable intake.
Potential limitations include selection and information bias. However, participation of cases and controls was high and similar, and attention was paid in excluding from the control group subjects who were admitted for any condition that might have affected dietary habits. Furthermore, cases and controls came from comparable catchment areas and were interviewed by the same trained personnel in a hospital setting ${ }^{(51)}$. Among the strengths are the large sample size, the use of a reproducible and valid $\mathrm{FFQ}^{(24,25)}$, and the ability to adjust for a number of potential confounding factors for the cancers investigated, as well as energy intake.

In terms of population-attributable risks, 20-60\% of digestive tract cancers in Italy could be attributable to low consumption of vegetables and fruit. In particular, the risks attributable to low consumption of vegetables and fruit in men and women were 25 and $17 \%$ for oral and pharyngeal cancer, 40 and $29 \%$ for oesophageal cancer, and 18 and $15 \%$ for laryngeal cancer, respectively ${ }^{(52)}$. In both sexes combined, the attributable risks were $60 \%$ for stomach cancer and $43 \%$ for colorectal cancer. For breast cancer, the attributable risk was $21 \%{ }^{(52)}$.

The favourable effect of vegetables and fruit against most forms of cancers has been related to several of their constituents, in the absence, however, of a clear understanding on which of these may be the key relevant ones. Indeed, vegetables and fruit are sources of a wide variety of micronutrients and other bioactive compounds, including carotenoids, folate, vitamins $\mathrm{C}, \mathrm{D}$ and $\mathrm{E}$ as well as vitamin $\mathrm{B}_{6}$, flavonoids, dietary fibre and selenium. These may act against cancer through their antioxidant activities, free radical-trapping capacity, modulation of detoxification enzymes, anti-mutagenic and anti-proliferative properties, stimulation of the immune system, as well as modulation of hormone concentration and hormone metabolism ${ }^{(53)}$. Ascorbic acid, carotenoids and other antioxidant vitamins were inversely related to upper digestive and respiratory tract neoplasms ${ }^{(9,54)}$. Likewise, lycopene was inversely related to several digestive tract neoplasms, and carotenoids, vitamin $\mathrm{E}$ and calcium showed an inverse relationship with breast cancer $^{(9,54)}$. However, despite the promising results of several dietary vitamins and food components on cancer risk from epidemiological studies, trials usually failed to show a protective effect of vitamin supplementation on cancer risk ${ }^{(55)}$.

Interestingly, a varied diet including several different types of fruit and vegetables was protective against several cancers in our data ${ }^{(56-60)}$. Different fruits and vegetables contain many different bioactive compounds, and these may exert synergistic interaction. It is, therefore, possible that a combination of plant-based bioactive components has a favourable role in cancer risk.

Given the high correlation between several micronutrients, it is difficult to disentangle their role and detect which specific component or group of components is responsible for a protective role against cancer. Since several antioxidants may influence cancer risk and act to prevent carcinogenesis, examining overall antioxidant exposure rather than individual antioxidants has recently been proposed. Inverse relationships of the Non-Enzymatic Antioxidant Capacity 
(NEAC) from diet, measured in terms of ferric reducingantioxidant power (FRAP), Trolox equivalent antioxidant capacity (TEAC) and total radical-trapping antioxidant parameter (TRAP), were reported in our studies for colorectal and stomach cancer ${ }^{(61)}$. The OR of colorectal cancer for the highest $v$. the lowest quintiles were 0.68 (95\% CI $0.57,0.82$ ) for FRAP, $0.69(95 \%$ CI $0.57,0.83)$ for TEAC and $0.69(95 \%$ CI $0.57,0.83)$ for TRAP ${ }^{(61)}$. The corresponding OR for stomach cancer were 0.54 (95\% CI 0.33, 0.88) for FRAP, 0.67 (95\% CI $0.42,1.07)$ for TEAC and 0.57 (95\% CI $0.39,0.90)$ for TRAP, respectively (submitted).

The beneficial effect of high intakes of vegetables and fruit in these studies may be also due, at least in part, to the fact that their high consumption often accompanies lower intakes of foods that may be positively related to the risk of cancer. They may, therefore, represent a general indicator of healthy dietary and lifestyle habits. Indeed, high intakes of fruit and vegetables are key features of the Mediterranean $\operatorname{diet}^{(62)}$, which has been inversely related to overall mortality as well as to specific health outcomes including CVD and cerebrovascular diseases, as well as cancer ${ }^{(1,2,6,8)}$.

A beneficial role of vegetable and fruit consumption in the risk of cancer has been reported either from a number of case-control studies ${ }^{(63-65)}$ or from some large cohort investigations $^{(66-72)}$. However, also a number of prospective studies, which generally have a higher level of evidence than case-control studies, have reported null associations, casting some doubts about the possible benefits of high vegetable and fruit consumption ${ }^{(73-77)}$. Findings from the European Prospective Investigation into Cancer and Nutrition (EPIC) study, across ten countries, have supported significant inverse associations between fruit consumption and upper aero-digestive tract cancers (mouth, pharynx, larynx and oesophagus) and lung cancer (in smokers), as well as between fruit and vegetable consumptions and colorectal cancer. For the other cancer sites considered (i.e. stomach, pancreas, breast, cervix, prostate, bladder and lymphoma), no significant association was reported for both fruit and vegetables consumption $^{(78)}$. The combined analysis of two major US cohorts, the Nurses' Health Study and the Health Professionals' Follow-up Study (HPFS), indicated no relevant role of fruit and vegetable intake on overall cancer incidence ${ }^{(75)}$ as well as on colon and rectal cancer ${ }^{(76)}$, but suggested possible inverse associations with kidney cancer ${ }^{(71)}$, premenopausal breast cancer ${ }^{(79)}$ and lung cancer in women but not in men ${ }^{(80)}$. Prospective data from the Netherlands Cohort Study on Diet and Cancer have shown a favourable role of vegetable and fruit intake in colorectal ${ }^{(81)}$ and lung cancers ${ }^{(82)}$, and no significant association with pancreatic ${ }^{(77)}$, ovarian $^{(83)}$, kidney ${ }^{(84)}$ and breast cancers ${ }^{(85)}$. Moreover, high intake of fruit, but not vegetables, reduced urothelial cancer risk ${ }^{(86)}$, and intakes of specific groups of vegetables (e.g. raw vegetables) and fruits (e.g. citrus fruits) were inversely related to subtypes of oesophageal and stomach cancers ${ }^{(87)}$. The Pooling Project of prospective Studies of Diet and Cancer, an international consortium of prospective cohort studies ${ }^{(88)}$, found no association between fruit and vegetable consumption and the risk of breast cancer overall (but an inverse association for oestrogen receptor-negative breast tumours; twenty cohorts/ 24690 cases) $^{(89)}$, pancreatic cancer (fourteen cohorts/ 2212 cases ${ }^{(90)}$, colon cancer overall (but an inverse association for distal colon cancer; fourteen cohorts/5838 cases) ${ }^{(91)}$ and ovarian cancer (twelve cohorts/2130 cases) ${ }^{(92)}$; a modest inverse association with lung cancer (eight cohorts/3206 cases $)^{(93)}$; and a significant inverse association with kidney cancer (thirteen cohorts/1474 cases) ${ }^{(94)}$.

In conclusion, our findings, as well as those from other studies conducted in Mediterranean countries ${ }^{(95,96)}$, indicate a large favourable effect of vegetable and fruit intake on the risk of several cancer sites, and this may well be due to the relative abundance of vegetables and fruit in the Mediterranean diet.

\section{Acknowledgements}

The present review was supported by the Italian Foundation for Cancer Research (FIRC) and by the Italian Ministry of Health, General Directorate of European and International Relations. F. T. was supported by a fellowship from the FIRC.

The authors' contributions are as follows: C. L. V. and F. L. designed and carried out the study; F. T. and M. R. drafted the article; C. P. and C. L. V. revised the paper critically for important intellectual content.

None of the authors has any conflicts of interest to declare.

\section{References}

1. Trichopoulou A, Kouris-Blazos A, Wahlqvist ML, et al. (1995) Diet and overall survival in elderly people. BMJ 311, $1457-1460$.

2. Trichopoulou A, Costacou T, Bamia C, et al. (2003) Adherence to a Mediterranean diet and survival in a Greek population. $N$ Engl J Med 348, 2599-2608.

3. Praud D, Bertuccio P, Bosetti C, et al. (2013) Adherence to the Mediterranean diet and gastric cancer risk in Italy. Int J Cancer 134, 2935-2941.

4. Turati F, Trichopoulos D, Polesel J, et al. (2013) Mediterranean diet and hepatocellular carcinoma. J Hepatol 60, 606-611.

5. Bosetti C, Turati F, Dal Pont A, et al. (2013) The role of Mediterranean diet on the risk of pancreatic cancer. Br J Cancer 109, 1360-1366.

6. Couto E, Boffetta P, Lagiou P, et al. (2011) Mediterranean dietary pattern and cancer risk in the EPIC cohort. $\mathrm{Br} J$ Cancer 104, 1493-1499.

7. Bamia C, Lagiou P, Buckland G, et al. (2013) Mediterranean diet and colorectal cancer risk: results from a European cohort. Eur J Epidemiol 28, 317-328.

8. Giacosa A, Barale R, Bavaresco L, et al. (2013) Cancer prevention in Europe: the Mediterranean diet as a protective choice. Eur J Cancer Prev 22, 90-95.

9. World Cancer Research Fund/American Institute for Cancer Research (2007) Food, Nutrition, Physical Activity, and The Prevention of Cancer: A Global Perspective. Washington, DC: American Institute for Cancer Research.

10. Bravi F, Bosetti C, Filomeno M, et al. (2013) Foods, nutrients and the risk of oral and pharyngeal cancer. Br J Cancer $\mathbf{1 0 9}$, $2904-2910$. 
11. Polesel J, Serraino D, Negri E, et al. (2013) Consumption of fruit, vegetables, and other food groups and the risk of nasopharyngeal carcinoma. Cancer Causes Control 24, 1157-1165.

12. Bosetti C, La Vecchia C, Talamini R, et al. (2000) Food groups and risk of squamous cell esophageal cancer in northern Italy. Int J Cancer 87, 289-294.

13. Lucenteforte E, Scita V, Bosetti C, et al. (2008) Food groups and alcoholic beverages and the risk of stomach cancer: a case-control study in Italy. Nutr Cancer 60, 577-584.

14. Franceschi S, Favero A, La Vecchia C, et al. (1997) Food groups and risk of colorectal cancer in Italy. Int J Cancer 72, 56-61.

15. Talamini R, Polesel J, Montella M, et al. (2006) Food groups and risk of hepatocellular carcinoma: a multicenter casecontrol study in Italy. Int J Cancer 119, 2916-2921.

16. Polesel J, Talamini R, Negri E, et al. (2010) Dietary habits and risk of pancreatic cancer: an Italian case-control study. Cancer Causes Control 21, 493-500.

17. Bosetti C, La Vecchia C, Talamini R, et al. (2002) Food groups and laryngeal cancer risk: a case-control study from Italy and Switzerland. Int J Cancer 100, 355-360.

18. Franceschi S, Favero A, La Vecchia C, et al. (1995) Influence of food groups and food diversity on breast cancer risk in Italy. Int J Cancer 63, 785-789.

19. Bravi F, Scotti L, Bosetti C, et al. (2009) Food groups and endometrial cancer risk: a case-control study from Italy. Am J Obstet Gynecol 200, 293 e291-e297.

20. Bosetti C, Negri E, Franceschi S, et al. (2001) Diet and ovarian cancer risk: a case-control study in Italy. Int J Cancer $\mathbf{9 3}$, 911-915.

21. Bosetti C, Micelotta S, Dal Maso L, et al. (2004) Food groups and risk of prostate cancer in Italy. Int $J$ Cancer 110, 424-428.

22. Bravi F, Bosetti C, Scotti L, et al. (2007) Food groups and renal cell carcinoma: a case-control study from Italy. Int $J$ Cancer 120, 681-685.

23. Talamini R, Polesel J, Montella M, et al. (2006) Food groups and risk of non-Hodgkin lymphoma: a multicenter, casecontrol study in Italy. Int J Cancer 118, 2871-2876.

24. Decarli A, Franceschi S, Ferraroni M, et al. (1996) Validation of a food-frequency questionnaire to assess dietary intakes in cancer studies in Italy. Results for specific nutrients. Ann Epidemiol 6, 110-118.

25. Franceschi S, Negri E, Salvini S, et al. (1993) Reproducibility of an Italian food frequency questionnaire for cancer studies: results for specific food items. Eur J Cancer 29A, 2298-2305.

26. Bosetti C, Filomeno M, Riso P, et al. (2012) Cruciferous vegetables and cancer risk in a network of case-control studies. Ann Oncol 23, 2198-2203.

27. Galeone C, Pelucchi C, Levi F, et al. (2006) Onion and garlic use and human cancer. Am J Clin Nutr 84, 1027-1032.

28. Galeone C, Pelucchi C, Dal Maso L, et al. (2009) Allium vegetables intake and endometrial cancer risk. Public Health Nutr 12, 1576-1579.

29. Turati F, Pelucchi C, Guercio V, et al. (2014) Allium vegetable intake and gastric cancer: a case-control study and metaanalysis. Mol Nutr Food Res 59, 171-179.

30. Foschi R, Pelucchi C, Dal Maso L, et al. (2010) Citrus fruit and cancer risk in a network of case-control studies. Cancer Causes Control 21, 237-242.

31. Gallus S, Talamini R, Giacosa A, et al. (2005) Does an apple a day keep the oncologist away? Ann Oncol 16, 1841-1844.

32. La Vecchia C (2002) Tomatoes, lycopene intake, and digestive tract and female hormone-related neoplasms. Exp Biol Med (Maywood) 227, 860-863.
33. La Vecchia C (1998) Mediterranean epidemiological evidence on tomatoes and the prevention of digestive-tract cancers. Proc Soc Exp Biol Med 218, 125-128.

34. Negri E, Franceschi S, Parpinel M, et al. (1998) Fiber intake and risk of colorectal cancer. Cancer Epidemiol Biomarkers Prev 7, 667-671.

35. Soler M, Bosetti C, Franceschi S, et al. (2001) Fiber intake and the risk of oral, pharyngeal and esophageal cancer. Int J Cancer 91, 283-287.

36. Bravi F, Scotti L, Bosetti C, et al. (2009) Dietary fiber and stomach cancer risk: a case-control study from Italy. Cancer Causes Control 20, 847-853.

37. Bidoli E, Pelucchi C, Zucchetto A, et al. (2010) Fiber intake and endometrial cancer risk. Acta Oncol 49, 441-446.

38. Bidoli E, Pelucchi C, Zucchetto A, et al. (2012) Fiber intake and pancreatic cancer risk: a case-control study. Ann Oncol 23, 264-268.

39. Bidoli E, Pelucchi C, Polesel J, et al. (2013) Fiber intake and risk of nasopharyngeal carcinoma: a case-control study. Nutr Cancer 65, 1157-1163.

40. Pelucchi C, Talamini R, Levi F, et al. (2003) Fibre intake and laryngeal cancer risk. Ann Oncol 14, 162-167.

41. Pelucchi C, Talamini R, Galeone C, et al. (2004) Fibre intake and prostate cancer risk. Int J Cancer 109, 278-280.

42. Galeone C, Pelucchi C, Talamini R, et al. (2007) Fibre intake and renal cell carcinoma: a case-control study from Italy. Int J Cancer 121, 1869-1872.

43. La Vecchia C \& Chatenoud L (1998) Fibres, whole-grain foods and breast and other cancers. Eur J Cancer Prev 7, Suppl. 2, S25-S28.

44. Pelucchi C, La Vecchia C, Chatenoud L, et al. (2001) Dietary fibres and ovarian cancer risk. Eur J Cancer 37, 2235-2239.

45. Rossi M, Negri E, Bosetti C, et al. (2010) Epidemiology behind fruit and vegetable consumption and cancer risk with focus on flavonoids. In Plant Phenolics and Human Health Biochemistry, Nutrition, and Pharmacology, pp. 471-487 [CG Fraga, editor]. Hoboken, New Jersey: John Wiley \& Sons, Inc.

46. Rossi M, Bosetti C, Negri E, et al. (2010) Flavonoids, proanthocyanidins, and cancer risk: a network of casecontrol studies from Italy. Nutr Cancer 62, 871-877.

47. Rossi M, Rosato V, Bosetti C, et al. (2010) Flavonoids, proanthocyanidins, and the risk of stomach cancer. Cancer Causes Control 21, 1597-1604.

48. Rossi M, Negri E, Parpinel M, et al. (2010) Proanthocyanidins and the risk of colorectal cancer in Italy. Cancer Causes Control 21, 243-250.

49. Rossi M, Lugo A, Lagiou P, et al. (2012) Proanthocyanidins and other flavonoids in relation to pancreatic cancer: a case-control study in Italy. Ann Oncol 23, 1488-1493.

50. Rossi M, Edefonti V, Parpinel M, et al. (2013) Proanthocyanidins and other flavonoids in relation to endometrial cancer risk: a case-control study in Italy. $B r J$ Cancer 109, 1914-1920.

51. D’Avanzo B, La Vecchia C, Katsouyanni K, et al. (1997) An assessment, and reproducibility of food frequency data provided by hospital controls. Eur J Cancer Prev 6, 288-293.

52. La Vecchia C, Altieri A \& Tavani A (2001) Vegetables, fruit, antioxidants and cancer: a review of Italian studies. Eur J Nutr 40, 261-267.

53. Steinmetz KA \& Potter JD (1991) Vegetables, fruit, and cancer. II. Mechanisms. Cancer Causes Control 2, 427-442.

54. Pelucchi C, Bosetti C, Rossi M, et al. (2009) Selected aspects of Mediterranean diet and cancer risk. Nutr Cancer 61 , $756-766$. 
55. Willett WC (2000) Diet and cancer. Oncologist 5, 393-404.

56. Lucenteforte E, Garavello W, Bosetti C, et al. (2008) Diet diversity and the risk of squamous cell esophageal cancer. Int J Cancer 123, 2397-2400.

57. Garavello W, Giordano L, Bosetti C, et al. (2008) Diet diversity and the risk of oral and pharyngeal cancer. Eur J Nutr 47, 280-284

58. Garavello W, Lucenteforte E, Bosetti C, et al. (2009) Diet diversity and the risk of laryngeal cancer: a case-control study from Italy and Switzerland. Oral Oncol 45, 85-89.

59. Fernandez E, Negri E, La Vecchia C, et al. (2000) Diet diversity and colorectal cancer. Prev Med 31, 11-14.

60. La Vecchia C, Munoz SE, Braga C, et al. (1997) Diet diversity and gastric cancer. Int J Cancer 72, 255-257.

61. La Vecchia C, Decarli A, Serafini M, et al. (2013) Dietary total antioxidant capacity and colorectal cancer: a large case-control study in Italy. Int J Cancer 133, 1447-1451.

62. Trichopoulou A, Bamia C \& Trichopoulos D (2009) Anatomy of health effects of Mediterranean diet: Greek EPIC prospective cohort study. BMJ 338, b2337.

63. Chuang SC, Jenab M, Heck JE, et al. (2012) Diet and the risk of head and neck cancer: a pooled analysis in the INHANCE consortium. Cancer Causes Control 23, 69-88.

64. Littman AJ, Beresford SA \& White E (2001) The association of dietary fat and plant foods with endometrial cancer (United States). Cancer Causes Control 12, 691-702.

65. Lindblad P, Wolk A, Bergstrom R, et al. (1997) Diet and risk of renal cell cancer: a population-based case-control study. Cancer Epidemiol Biomarkers Prev 6, 215-223.

66. Terry P, Giovannucci E, Michels KB, et al. (2001) Fruit, vegetables, dietary fiber, and risk of colorectal cancer. J Natl Cancer Inst 93, 525-533.

67. Terry P, Nyren O \& Yuen J (1998) Protective effect of fruits and vegetables on stomach cancer in a cohort of Swedish twins. Int J Cancer 76, 35-37.

68. Michaud DS, Spiegelman D, Clinton SK, et al. (1999) Fruit and vegetable intake and incidence of bladder cancer in a male prospective cohort. J Natl Cancer Inst 91, 605-613.

69. Freedman ND, Park Y, Subar AF, et al. (2007) Fruit and vegetable intake and esophageal cancer in a large prospective cohort study. Int J Cancer 121, 2753-2760.

70. Gonzalez CA, Pera G, Agudo A, et al. (2006) Fruit and vegetable intake and the risk of stomach and oesophagus adenocarcinoma in the European Prospective Investigation into Cancer and Nutrition (EPIC-EURGAST). Int $J$ Cancer 118, 2559-2566.

71. Lee JE, Giovannucci E, Smith-Warner SA, et al. (2006) Intakes of fruits, vegetables, vitamins $\mathrm{A}, \mathrm{C}$, and $\mathrm{E}$, and carotenoids and risk of renal cell cancer. Cancer Epidemiol Biomarkers Prev 15, 2445-2452.

72. Flood A, Velie EM, Chaterjee N, et al. (2002) Fruit and vegetable intakes and the risk of colorectal cancer in the Breast Cancer Detection Demonstration Project follow-up cohort. Am J Clin Nutr 75, 936-943.

73. van Gils $\mathrm{CH}$, Peeters $\mathrm{PH}$, Bueno-de-Mesquita $\mathrm{HB}$, et al (2005) Consumption of vegetables and fruits and risk of breast cancer. JAMA 293, 183-193.

74. Weikert S, Boeing H, Pischon T, et al. (2006) Fruits and vegetables and renal cell carcinoma: findings from the European prospective investigation into cancer and nutrition (EPIC). Int J Cancer 118, 3133-3139.

75. Hung HC, Joshipura KJ, Jiang R, et al. (2004) Fruit and vegetable intake and risk of major chronic disease. J Natl Cancer Inst 96, 1577-1584.
76. Michels KB, Edward G, Joshipura KJ, et al. (2000) Prospective study of fruit and vegetable consumption and incidence of colon and rectal cancers. J Natl Cancer Inst 92, 1740-1752.

77. Heinen MM, Verhage BA, Goldbohm RA, et al. (2012) Intake of vegetables, fruits, carotenoids and vitamins $\mathrm{C}$ and $\mathrm{E}$ and pancreatic cancer risk in The Netherlands Cohort Study. Int J Cancer 130, 147-158.

78. Bradbury KE, Appleby PN \& Key TJ (2014) Fruit, vegetable, and fiber intake in relation to cancer risk: findings from the European Prospective Investigation into Cancer and Nutrition (EPIC). Am J Clin Nutr 100, 394S-398S

79. Zhang S, Hunter DJ, Forman MR, et al. (1999) Dietary carotenoids and vitamins $\mathrm{A}, \mathrm{C}$, and $\mathrm{E}$ and risk of breast cancer. J Natl Cancer Inst 91, 547-556.

80. Feskanich D, Ziegler RG, Michaud DS, et al. (2000) Prospective study of fruit and vegetable consumption and risk of lung cancer among men and women. I Natl Cancer Inst 92, 1812-1823

81. Voorrips LE, Goldbohm RA, van Poppel G, et al. (2000) Vegetable and fruit consumption and risks of colon and rectal cancer in a prospective cohort study: The Netherlands Cohort Study on Diet and Cancer. Am J Epidemiol 152, 1081-1092.

82. Voorrips LE, Goldbohm RA, Verhoeven DT, et al. (2000) Vegetable and fruit consumption and lung cancer risk in the Netherlands Cohort Study on diet and cancer. Cancer Causes Control 11, 101-115.

83. Mommers M, Schouten LJ, Goldbohm RA, et al. (2005) Consumption of vegetables and fruits and risk of ovarian carcinoma. Cancer 104, 1512-1519.

84. van Dijk BA, Schouten LJ, Kiemeney LA, et al. (2005) Vegetable and fruit consumption and risk of renal cell carcinoma: results from the Netherlands cohort study. Int $J$ Cancer 117, 648-654.

85. Verhoeven DT, Assen N, Goldbohm RA, et al. (1997) Vitamins $\mathrm{C}$ and $\mathrm{E}$, retinol, beta-carotene and dietary fibre in relation to breast cancer risk: a prospective cohort study. Br J Cancer 75, 149-155.

86. Zeegers MP, Goldbohm RA \& van den Brandt PA (2001) Consumption of vegetables and fruits and urothelial cancer incidence: a prospective study. Cancer Epidemiol Biomarkers Prev 10, 1121-1128.

87. Steevens J, Schouten LJ, Goldbohm RA, et al. (2011) Vegetables and fruits consumption and risk of esophageal and gastric cancer subtypes in the Netherlands Cohort Study. Int J Cancer 129, 2681-2693.

88. Smith-Warner SA, Spiegelman D, Ritz J, et al. (2006) Methods for pooling results of epidemiologic studies: the Pooling Project of Prospective Studies of Diet and Cancer. Am I Epidemiol 163, 1053-1064

89. Jung S, Spiegelman D, Baglietto L, et al. (2013) Fruit and vegetable intake and risk of breast cancer by hormone receptor status. J Natl Cancer Inst 105, 219-236.

90. Koushik A, Spiegelman D, Albanes D, et al. (2012) Intake of fruits and vegetables and risk of pancreatic cancer in a pooled analysis of 14 cohort studies. Am J Epidemiol 176, 373-386

91. Koushik A, Hunter DJ, Spiegelman D, et al. (2007) Fruits, vegetables, and colon cancer risk in a pooled analysis of 14 cohort studies. J Natl Cancer Inst 99, 1471-1483.

92. Koushik A, Hunter DJ, Spiegelman D, et al. (2005) Fruits and vegetables and ovarian cancer risk in a pooled analysis of 12 cohort studies. Cancer Epidemiol Biomarkers Prev 14, $2160-2167$. 
93. Smith-Warner SA, Spiegelman D, Yaun SS, et al. (2003) Fruits, vegetables and lung cancer: a pooled analysis of cohort studies. Int J Cancer 107, 1001-1011.

94. Lee JE, Mannisto S, Spiegelman D, et al. (2009) Intakes of fruit, vegetables, and carotenoids and renal cell cancer risk: a pooled analysis of 13 prospective studies. Cancer Epidemiol Biomarkers Prev 18, 1730-1739.
95. Benetou V, Orfanos P, Lagiou P, et al. (2008) Vegetables and fruits in relation to cancer risk: evidence from the Greek EPIC cohort study. Cancer Epidemiol Biomarkers Prev 17, 387-392.

96. Masala G, Assedi M, Bendinelli B, et al. (2012) Fruit and vegetables consumption and breast cancer risk: the EPIC Italy study. Breast Cancer Res Treat 132, 1127-1136. 